\title{
Komparasi Metode WP SAW dan WASPAS Dalam Penentuan Penerima Beasiswa Penelusuran Minat dan Kemampuan
}

\author{
Veradilla Amalia ${ }^{1}$, Dedy Syamsuar ${ }^{2}$, Linda Atika ${ }^{3}$ \\ ${ }^{1}$ Program Studi Magister Teknik Informatika, Universitas Bina Darma, Palembang \\ veradillaamalia@gmail.com \\ ${ }^{2,3}$ Dosen Universitas Bina Darma Palembang \\ dedy_syamsuar@binadarma.ac.id, linda.atika@binadarma.ac.id
}

\begin{abstract}
Abstrak
STMIK Bina Nusantara Jaya Lubuklinggau menawarkan beasiswa Penelusuran Minat dan Kemampuan (PMDK) kepada calon mahasiswa baru, dalam hal ini untuk melakukan proses seleksi penentuan penerima beasiswa PMDK pengolahan data masih dilakukan secara manual dengan melakukan tes wawancara dan melakukan perhitungan hasil dari wawancara. Proses seleksi yang dilakukan secara manual memiliki beberapa kelemahan sehingga besar kemungkinan akan terjadinya kesalahan dalam pengolahan data. Untuk Itu diperlukannya suatu Sistem Pendukung Keputusan yang dapat mempermudah dalam penentuan penerima beasiswa PMDK. Pada penelitian ini menggunakan analisa perhitungan komparasi metode WP, SAW dan WASPAS dalam penentuan penerima beasiswa penelusuran minat dan kemampuan (PMDK). Sistem dibuat menggunakan metode SAW karena memberikan nilai Alternatif tertinggi dan memberikan hasil perangkingan yang terbaik.
\end{abstract}

Kata kunci : Sistem Pendukung Keputusan, WP, SAW, WASPAS.

\begin{abstract}
STMIK Bina Nusantara Jaya Lubuklinggau offers scholarships for Searching for Interest and Capability (PMDK) for prospective new students, in this case to conduct a selection process for determining recipients of PMDK scholarship data processing is still done manually by conducting interview tests and calculating the results of interviews. The manual selection process has several disadvantages, so there is a high probability of errors in data processing. For this reason, a Decision Support System is needed that can facilitate the determination of PMDK scholarship recipients. In this study, the analysis of the comparative calculation of the WP, SAW and WASPAS methods was used in determining scholarship recipients to explore interests and abilities (PMDK). The system is made using the SAW method because it provides the highest Alternative value and gives the best ranking results.
\end{abstract}

Keywords : Decision Support System, WP, SAW, WASPAS

\section{Pendahuluan}

Proses seleksi penerima beasiswa merupakan tahapan penting yang membutuhkan ketelitian dan ketepatan agar beasiswa dapat diberikan kepada penerima yang tepat. Beasiswa itu sendiri merupakan uang yang diberikan untuk biaya belajar Ali. (n.d.). Proses seleksi penentuan penerima beasiswa Penelusuran Minat dan Kemampuan (PMDK) pengolahan data masih dilakukan secara manual dan belum terkomputerisasi. Proses seleksi yang dilakukan secara manual memiliki beberapa kelemahan sehingga besar kemungkinan akan terjadinya kesalahan dalam pengolahan data dikarenakan kurang efisensinya waktu yang digunakan, proses seleksi dan pengolahan data calon penerima beasiswa PMDK pada STMIK Bina Nusantara Jaya Lubuklinggau selama ini dilakukan dengan beberapa tahapan, yakni; menyeleksi berkas calon mahasiswa 
penerima beasiswa PMDK, melakukan tes wawancara, melakukan perhitungan hasil wawancara,dan terakhir membuat range nilai hasil yang telah dihitung untuk dilaporkan kepada ketua.

Dalam menerapkan sistem pendukung keputusan sudah banyak cara atau metode yang telah digunakan seperti metode Simple Additive Weighting (SAW), Weighted Product (WP) dan metode Analytical Hierarchy Process (AHP) ada juga yang mengkomparasi atau membandingkan metode sistem pengambilan keputusan seperti yang dilakukan penetiti sebelumnya dengan melakukan perbandingan metode Simple Additive Weighting (SAW) dan metode Technique for Order Preference by Similiarity to Ideal Solution (TOPSIS) pada kasus UMKM yang diteliti oleh Mude, M. A. (2016) perbandian metode Simple Additive Weighting (SAW) dan metode Weighted Aggregated Sum Product Assessment (WASPAS) dalam pemilihan bibit manga terunggul oleh Soeb Aripin, Agus Adi Pramadi, Mulia Syahputra, A. M. S. (2018). dan penelitian sebelumnya dengan melakukan perbandingan metode SAW, WP dan Topsis dalam pemilihan supplier material yang diterliti oleh Hamberto, A., Katili, P. B., \& Ummi, N. (2013).

\section{Metode Penelitian}

\subsection{Konsep Model Penelitian}

Penelitian dirancang untuk menentukan penerima beasiswa PMDK dengan menggunakan metode pengembangan sistem fase Rational Unified Process (RUP) mulai tahap Inception, Elaboration, Construction, Transition. Menganalisa perhitungan dengan perbandingan metode Weighted Product (WP) metode Simple Additive Weighting (SAW) dan metode Simple Additive Weighting (SAW) dan metode Weighted Aggregated Sum Product (WASPAS). Penelitian menggunakan metode wawancara dimana dilakukan wawancara langsung dengan pihak pengelola beasiswa PMDK, Wawancara dilakukan guna mendapatkan informasi lebih lengkap mengenai permasalahan yang akan diteliti. Penelitian ini menggunakan penelitian bersifat kualitatif sering disebut metode penelitian naturalistik karena penelitiannya dilakukan pada kondisi alamiah (natural setting), dengan cara memahami dan menjabarkan permasalahan-permasalahan yang ada berdasarkan fakta dan data yang ada (Sugiyono, 2013).

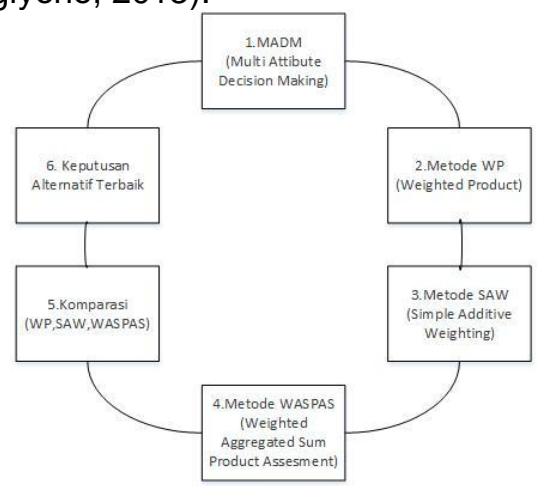

Gambar 1. Model Penelitian

\subsection{Tinjauan Pustaka}

Menurut Pratiwi (2016) Pengambilan keputusan dilakukan pimpinan untuk menyelesaikan masalah yang dihadapi dalam organisasi yang dipimpinnya dengan melakukan pemilihan satu alternative pemecahan masalah terbaik dengan berdasarkan pertimbangan-pertimbangan tertentu. Menurut Fitriyani (2012) Pengambilan keputusan merupakan proses pemilihan alternatif tindakan untuk mencapai tujuan atau sasaran tertentu. Pengambilan keputusan dilakukan dengan pendekatan sistematis terhadap permasalahan melalui proses pengumpulan data menjadi informasi serta ditambah dengan faktor-faktor yang perlu dipertimbangkan dalam pengambilan keputusan.

Menurut Pratiwi (2016) Tujuan Sistem Pendukung Keputusan terdiri dari tiga tujuan yang akan dicapai yaitu :

1. Membantu manajer membuat keputusan untuk memecahkan masalah semi terstruktur.

2. Mendukung penilaian manajer bukan mencoba menggantikannya.

3. Meningkatkan efektifitas pengambilan keputusan manajer dari pada efisiensinya.

Menurut Kusrini (2007) keputusan yang diambil untuk menyelesaikan suatu masalah dilihat dari keterstukturannya yang dibagi menjadi menjadi tiga yaitu keputusan terstruktur (structured decision), keputusan semiterstuktur (semistructured decision), keputusan tak terstuktur (unstructured decision).
a. Keputusan terstruktur (structured decision) 
Keputusan terstruktur adalah keputusan yang dilakukan secara berulang-ulang dan bersifat rutin.

b. Keputusan semiterstruktur (semistructured decision)

Keputusan semiterstuktur adalah keputusan yang memiliki dua sifat. Sebagian keputusan biasa ditangani oleh komputer dan yang lain tetap harus dilakukan oleh pengambil keputusan.

c. Keputusan tak tersturktur (unstructured decision)

Keputusan tak terstuktur adalah keputusan yang penanganannya rumit karena tidak terjadi berulang-ulang atau tidak selalu terjadi. Keputusan tersebut menuntut pengalaman dan berbagai sumber yang bersifat eksternal

Dalam penentuan calon penerima beasiswa yang kurang mampu, peneliti memper-timbangkan kriteria-kriteria yang akan digunakan untuk memilih calon penerima beasiswa yaitu: 1) aspek akademik 2) aspek kepribadian dan 3) aspek keluarga (Junaidi \& Visella, 2017)

\subsection{Metode Weighted Product (WP)}

Weighted Product (WP) merupakan salah satu metode sistem pendukung keputusan, dimana perkalian digunakan untuk menghubungkan rating atibut, dan rating setiap atribut harus dipangkatkan dulu dengan bobot atribut yang bersangkutan (Agus, 2017).

Langkah-langkah metode Weighted Product (WP) :

1. Menentukan kriteria-kriteria yang akan dijadikan acuan dalam pengambilan keputusan

2. Mengkonversi inputan data kriteria menjadi nilai rating kecocokan

3. Melakukan perbaikan nilai bobot dari setiap kriteria dengan rumus

$$
W_{j}=\frac{W_{j}}{\sum W_{j}}
$$

4. Menetukan nilai preferensi untuk alternatif Si dengan rumus

$$
S_{i}=\prod_{j=1}^{n} X_{i j} W_{j}
$$

5. Menghitung nilai preferensi $V_{i}$ untuk setiap alternatif menggunakan rumus

$$
\mathbf{V}_{\mathrm{i}}=\frac{\prod_{j=1}^{n} X_{i j} w_{j}}{\prod_{j=1}^{n}\left(W_{j}\right) W_{j}}
$$

Keterangan :

S :Preferensi alternatif diabalogikan sebagai vector $\mathrm{S}$

$\mathrm{V}$ : Nilai vector untuk perangkingan
$X$ : Nilai alternative setiap kriteria

W: Bobot kriteria

I : Alternatif

j : Kriteria

n : Banyaknya kriteria

\subsection{Metode Simple Additive Weighting (SAW)}

Simple Additive Weighting (SAW) sering juga dikenal metode Penjumlahan terbobot. Konsep dasar metode SAW adalah mencari penjumlahan terbobot dari rating kinerja pada setiap alternatif pada semua atribut. Metode SAW mengharuskan pembuat keputusan menentukan bobot bagi setiap atribut.

Langkah-langkah menggunakan metode SAW adalah sebagai berikut (Targiono, 2017) :

1. Menentukan kriteria-kriteria yang akan dijadikan acuan dalam pengambilan keputusan yaitu $\mathrm{C}_{\mathrm{i}}$.

2. Menentukan rating kecocokan setiap alternatif pada setiap kriteria..

3. Membuat matrik keputusan berdasarkan $\left(\mathrm{C}_{\mathrm{i}}\right)$, kemudian melakukan normalisasi matrik berdasarkan persamaan jenis atribut benefit atau atribut cost sehingga diperoleh matrik ternomalisasi $\mathrm{R}$ dengan rumus:

$$
\begin{aligned}
& \text { Untuk Benefit } \\
& \mathbf{R}_{\mathrm{ij}}=\frac{\boldsymbol{X}_{i j}}{\boldsymbol{M a x} \boldsymbol{X}_{i j}} \\
& \text { Untuk Cost }
\end{aligned}
$$

\section{Keterangan :}

$$
\mathbf{R}_{\mathrm{ij}}=\frac{M i x X_{i j}}{X_{i j}}
$$

$\mathrm{R}_{\mathrm{ij}} \quad$ : Rating ternormalisasi

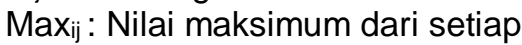
baris dan kolom

Min $_{\mathrm{ij}}$ : Nilai minimum dari setiap baris dan kolom

$\boldsymbol{X}_{\boldsymbol{i} j} \quad$ : Baris dan kolom dari matrik

\subsection{Metode Weighted Aggregated Sum \\ Product Assessment (WASPAS)}

Metode penilaian jumlah pengumpulan berbobot WASPAS adalah kombinasi unik WSM dan metode WPM. Metode WASPAS digunakan untuk memecahkan berbagai masalah seperti pada pembuatan keputusan dan evaluasi alternative. Langkah proses perhitungan menerapkan metode WASPAS (Barus, Sitorus et al. 2018), yaitu:

1. Buat sebuah matriks keputusan 


$$
\mathrm{x}=\left[\begin{array}{lll}
X_{11} & X_{12} & \cdot X_{1 n} \\
X_{21} & X_{11} & \cdot X_{2 n} \\
X_{m 1} X_{m 1} \cdot & \dot{X}_{m n}
\end{array}\right]
$$

2. Melakukan normalisasi terhadap matrik $\mathrm{x}$

$$
\begin{aligned}
& \text { Kriteria Benefit } \\
& \ddot{X_{l J}}=\frac{X_{i j}}{\operatorname{maX}_{\mathrm{i}} x_{i j}} \\
& \text { Kriteria Cost } \\
& \ddot{X_{l \jmath}}=\frac{\min _{i X_{i j}}}{x_{i j}}
\end{aligned}
$$

Menghitung nilai Qi

$$
\begin{aligned}
& \mathrm{Qi}=0,5 \sum_{\mathrm{j}=1}^{\mathrm{n}} \mathrm{X}_{\mathrm{ij}} \mathrm{w}+0,5 \prod_{j=1}^{n}(x i j) \quad w j \\
& \text { Dimana : } \\
& \mathrm{Qi}: \text { Nilai dari Q ke } \mathrm{i} \\
& \mathrm{X}_{\mathrm{ij}} \mathrm{w}: \text { Perkalian nilai } \mathrm{X}_{\mathrm{ij}} \text { dengan } \\
& \text { bobot }(\mathrm{w}) \\
& 0,5: \text { Ketetapan }
\end{aligned}
$$

Alternatif yang terbaik merupakan alternatif yang memiliki nilai Qi tertinggi.

\subsection{Fase Rational Unified Process (RUP)}

Rational Unified Process (RUP) memiliki empat fase yang dapat dilakukan secara iterative A. S., Rosa dan M.Shalahudin (2018).

1. Inception (permulaan)

Tahap ini lebih pada memodelkan proses bisnis yang dibutuhkan (business modeling) dan mendefinisikan kebutuhan akan sistem yang akan dibut (requiremets).

2. Elaboration (perluasan/perencanaan)

Tahap ini lebih pada analisis dan desain sistem serta implementasi sistem yang focus pada purwarupa sistem (prototype).

3. Contruction (kontruksi)

Tahap ini lebih pada implentasi dan pengujian sistem yang focus pada implementasi perangkat lunak pada kode program. Tahap ini menghasilkan produk perangkat lunak dimana menjadi syarat dari Intial Operational Capability Milestone atau batas/tonggak kemampuan operasional awal.

4. Transition (Transisi)

Tahap ini lebih pada deployment atau instalasi sistem agar dapat dimengerti oleh user

\subsection{Teknik Analisa Data}

Analisa data yang dilakukan yaitu membuat instrument penelitian saat melakukan wawancara kemudian mengobservasi kecocokan dari hasil wawancara untuk pengembangan perangkat lunak dengan mengunakan fasefase RUP (Rational Unified Process) Untuk membangun suatu sistem pendukung keputusan penentuan penerimaan beasiswa program Penelusuran Minat dan Kemampuan (PMDK) dengan menggunakan metode terbaik hasil dari komparasi metode Weighted Product (WP), metode Simple Additive Weighting (SAW) dan metode Weighted Aggregated Sum Product (WASPAS) dalam menentukan penerima beasiswa PMDK. Penelitian ini menggunakan penelitian bersifat kualitatif sering disebut metode penelitian naturalistik karena penelitiannya dilakukan pada kondisi alamiah (natural setting), dengan cara memahami dan menjabarkan permasalahan-permasalahan yang ada berdasarkan fakta dan data yang ada (Sugiyono, 2013)

\section{Hasil dan Pembahasan 3.1 Kriteria}

Tahap awal adalah menganalisa kriteria sebagai dasar proses dilakukannya seleksi. Penentuan kriteria ini berdasarkan hasil wawancara dengan pihak pengelola beasiswa PMDK. Adapun kriteria yang digunakan adalah pekerjaan orang tua, penghasilan orang tua, jumlah tanggungan, prestasi akademik dan non akademik, dan status tempat tinggal.

Tabel 1. Data Kriteria

\begin{tabular}{|c|c|c|c|c|c|}
\hline Nama & $\begin{array}{c}\text { Pekerjaan } \\
\text { Ortu }\end{array}$ & $\begin{array}{c}\text { Peng } \\
\text { hasil } \\
\text { an }\end{array}$ & $\begin{array}{c}\text { Tanggu } \\
\text { ngan }\end{array}$ & $\begin{array}{c}\text { Prestasi } \\
\text { Akademi } \\
\mathbf{k} \text { \& Non }\end{array}$ & $\begin{array}{c}\text { Status } \\
\text { Tempat } \\
\text { Tinggal }\end{array}$ \\
\hline V1 & PNS & 3 & 3 & Ada & M \\
\hline V2 & Swasta & 2,3 & 2 & Ada & M \\
\hline V3 & Petani & 2 & 3 & Ada & M \\
\hline V4 & Petani & 2 & 2 & Ada & S \\
\hline V5 & Wiraswasta & 2,5 & 3 & - & MS \\
\hline V6 & Swasta & 2 & 2 & Ada & S \\
\hline V7 & PNS & 3 & 4 & - & MS \\
\hline V8 & Petani & 3 & 3 & Ada & S \\
\hline V9 & Swasta & 3 & 4 & Ada & S \\
\hline V10 & Wiraswasta & 2,8 & 3 & - & S \\
\hline
\end{tabular}




\subsection{Pembobotan}

Pembobotan dari kriteria tersebut diatas sebagai berikut :

1. Pekerjaan Orang Tua, dibobotkan menjadi :

Tabel 2. Pembobotan Pekerjaan Orang Tua

\begin{tabular}{|c|c|}
\hline Pekerjaan & Nilai \\
\hline PNS/TNI/POLRI & 4 \\
\hline Karyawan Swasta & 5 \\
\hline Wiraswasta & 6 \\
\hline Petani/Buruh/Ojek & 7 \\
\hline Tidak Bekerja & 8 \\
\hline
\end{tabular}

2. Penghasilan Orang Tua, dibobotkan menjadi :

Tabel 3. Pembobotan Penghasilan Orang Tua

\begin{tabular}{|c|c|}
\hline Penghasilan Orang Tua & Nilai \\
\hline$\leq 1$ Juta & 6 \\
\hline$\leq 2$ Juta & 5 \\
\hline$\leq 3$ Juta & 4 \\
\hline$\leq 4$ Juta & 3 \\
\hline$\leq 10$ Juta & 2 \\
\hline
\end{tabular}

3. Tanggungan Orang Tua, dibobotkan menjadi :

Tabel 4. Pembobotan Tanggungan Orang Tua

\begin{tabular}{|c|c|}
\hline Tanggungan Orang Tua & Nilai \\
\hline 1 & 1 \\
\hline 2 & 2 \\
\hline 3 & 3 \\
\hline 4 & 4 \\
\hline$\geq 5$ & 5 \\
\hline
\end{tabular}

4. Prestasi Akademik dan Non Akademik, dibobotkan menjadi :

Tabel 5. Pembobotan Prestasi

Akademik dan Non Akademik Prestasi Akademik Non $\quad$ Nilai Akademik

Ada

Tidak Ada

5. Status tempat tinggal, dibobotkan menjadi

Tabel 6. Pembobotan Status tempat tinggal

\begin{tabular}{|c|c|}
\hline Status Tempat Tinggal & Nilai \\
\hline Milik Sendiri (MS) & 7 \\
\hline Sewa (S) & 8 \\
\hline
\end{tabular}

\subsection{Rating Kecocokan}

Berdasarkan data kriteria dan pembobotan diatas maka langkah berikutnya membuat rating kecocokan seperti tabel berikut ini :

Tabel 7. Rating Kecocokan

\begin{tabular}{|l|c|c|c|c|c|}
\hline Nama & $\begin{array}{c}\text { Pekerjaa } \\
\text { n Ortu }\end{array}$ & $\begin{array}{c}\text { Penghasi } \\
\text { lan }\end{array}$ & $\begin{array}{c}\text { Tanggun } \\
\text { gan }\end{array}$ & $\begin{array}{c}\text { Prestasi } \\
\text { Akademik } \\
\text { \& Non }\end{array}$ & $\begin{array}{l}\text { Status } \\
\text { Tempat } \\
\text { Tinggal }\end{array}$ \\
\hline V1 & 4 & 4 & 3 & 8 & 7 \\
\hline V2 & 5 & 4 & 2 & 8 & 7 \\
\hline V3 & 7 & 5 & 3 & 8 & 7 \\
\hline V4 & 7 & 5 & 2 & 8 & 8 \\
\hline V5 & 6 & 4 & 3 & 7 & 7 \\
\hline V6 & 5 & 5 & 2 & 8 & 8 \\
\hline V7 & 4 & 4 & 4 & 7 & 7 \\
\hline V8 & 7 & 4 & 3 & 8 & 8 \\
\hline V9 & 5 & 4 & 4 & 8 & 8 \\
\hline V10 & 6 & 4 & 3 & 7 & 8 \\
\hline
\end{tabular}

\subsection{Perhitungan Metode Weighted Product} (WP)

Proses perhitungan menggunakan langkah-langkah metode WP yang telah dijelaskan diatas :

1) Bobot yang digunakan sebagai berikut menggunakan persamaan (1) :

Tabel 8. Bobot

\begin{tabular}{|c|r|r|r|r|r|}
\hline w & 0.3 & 0.2 & 0.15 & 0.2 & 0.15 \\
\hline
\end{tabular}

2) Menetukan nilai preferensi untuk alternatif Si menggunakan persamaan (2)

$\mathrm{S} 1=\left(4^{0,3}\right)\left(4^{-0,2}\right)\left(3^{0,15}\right)\left(8^{0,2}\right)\left(7^{0,15}\right)=2.748$ $\mathrm{S} 2=\left(5^{0,3}\right)\left(4^{-0,2}\right)\left(2^{0,15}\right)\left(8^{0,2}\right)\left(7^{0,15}\right)=2.765$

S3 dsb..... S10

3) Menghitung nilai preferensi $V_{i}$ untuk setiap alternative menggunakan persamaaan (3)

$$
\begin{aligned}
& \mathrm{V} 1=\frac{2.748}{2.748+2.765+3.109+2.985+3.022+2.698+2.794+3.317+3.130+3.083}=0.0926 \\
& V 2=\frac{2.765}{2.748+2.765+3.109+2.985+3.022+2.698+2.794+3.317+3.130+3.083}=0.0932
\end{aligned}
$$

V3 dsb.... V10

4) Hasil perangkingan dari yang tertinggi hingga yang terendah metode WP

Tabel 9. Tabel Perangkingan WP

\begin{tabular}{|c|c|}
\hline Alternatif & Hasil \\
\hline V8 & 0.1118 \\
\hline V9 & 0.1055 \\
\hline V3 & 0.1048 \\
\hline V10 & 0.1039 \\
\hline V5 & 0.1019 \\
\hline V4 & 0.1006 \\
\hline
\end{tabular}




\begin{tabular}{|c|l|}
\hline V7 & 0.0942 \\
\hline V2 & 0.0932 \\
\hline V1 & 0.0926 \\
\hline V6 & 0.0909 \\
\hline
\end{tabular}

3.5 Perhitungan Metode Simple Additive Weighting (SAW)

Proses perhitungan menggunakan langkahlangkah metode SAW yang telah dijelaskan diatas :

1) Membuat Matriks Keputusan menggunakan persamaan [4] dan [5] :

$\left[\begin{array}{ccccc}0.571 & 1 & 0.75 & 1 & 0.875 \\ 0.714 & 1 & 0.5 & 1 & 0.875 \\ 1 & 0.8 & 0.75 & 1 & 0.875 \\ 1 & 0.8 & 0.5 & 1 & 1 \\ 0.857 & 1 & 0.75 & 0.875 & 0.875 \\ 0.714 & 0.8 & 0.5 & 1 & 1 \\ 0.571 & 1 & 1 & 0.875 & 0.875 \\ 1 & 1 & 0.75 & 1 & 1 \\ 0.714 & 1 & 1 & 1 & 1 \\ 0.857 & 1 & 0.75 & 0.875 & 1\end{array}\right]$

2) Menghitung skor setiap alternatif untuk mencari alternatif terbaik menggunakan $\mathbf{V}_{1}$ persamaan [6] :

$=(0.3)(0.571)+(0.2)(1)+(0.15)(0.75)+(0$. $2)(1)+(0.15)(0.875)=\mathbf{0 . 8 1 5 0}$

$\mathrm{V}_{2}$

$=(0.3)(1)+(0.2)(0.6)+(0.15)(0.5)+(0.2)(0$ $.875)+(0.15)(1)=\mathbf{0 . 8 2}$

V3 dsb.... V10

3) Hasil perangkingan dari yang tertinggi hingga yang terendah metode SAW

Tabel 10. Tabel Perangkingan SAW

\begin{tabular}{|c|c|}
\hline Alternatif & Hasil \\
\hline V8 & 0.965 \\
\hline V9 & 0.914 \\
\hline V3 & 0.903 \\
\hline V10 & 0.893 \\
\hline V4 & 0.885 \\
\hline V5 & 0.875 \\
\hline V7 & 0.827 \\
\hline V2 & 0.820 \\
\hline V1 & 0.815 \\
\hline V6 & 0.799 \\
\hline
\end{tabular}

3.6 Perhitungan Metode Weight Aggregated Sum Product Assesment (WASPAS)

Proses perhitungan menggunakan langkah-langkah metode WASPAS yang telah dijelaskan diatas :
1) Buat sebuah matriks keputusan menggunakan persamaan [7] :

$$
\left[\begin{array}{lllll}
4 & 4 & 3 & 8 & 7 \\
5 & 4 & 2 & 8 & 7 \\
7 & 5 & 3 & 8 & 7 \\
7 & 5 & 2 & 8 & 8 \\
6 & 4 & 3 & 7 & 7 \\
5 & 5 & 2 & 8 & 8 \\
4 & 4 & 4 & 7 & 7 \\
7 & 4 & 3 & 8 & 8 \\
5 & 4 & 4 & 8 & 8 \\
6 & 4 & 3 & 7 & 8
\end{array}\right]
$$

2) Melakukan normalisasi terhadap matrik $x$ menggunakan persamaan [8] dan [9] :

$\left[\begin{array}{ccccc}0.571 & 1 & 0.75 & 1 & 0.875 \\ 0.714 & 1 & 0.5 & 1 & 0.875 \\ 1 & 0.8 & 0.75 & 1 & 0.875 \\ 1 & 0.8 & 0.5 & 1 & 1 \\ 0.857 & 1 & 0.75 & 0.875 & 0.875 \\ 0.714 & 0.8 & 0.5 & 1 & 1 \\ 0.571 & 1 & 1 & 0.875 & 0.875 \\ 1 & 1 & 0.75 & 1 & 1 \\ 0.714 & 1 & 1 & 1 & 1 \\ 0.857 & 1 & 0.75 & 0.875 & 1\end{array}\right]$

3) Menghitung Nilai $\mathbf{Q}$; atarelatif dari alternative menggunakan persamaan [10]:

$\mathrm{Q}_{1}=$

$(0,5) \sum(0.571 * 0.3)(1 * 0.2)(0.75 * 0.15)(1 * 0.2)(0.875 * 0.15)$

$(0,5) \sum(0.1713+0.2+0.1125+0.2+0.1312)$

$0,5 * 0.815=0.4076$

$(0,5) \prod(0.571)^{0.3 *}(1)^{0.2 *}(0.75)^{0.15 *}(1)^{0.2 *}(0.875)^{0.15}$

$(0,5) \prod(0.8452 * 1 * 0.958 * 1 * 0.9801)$

$0,5 * 0.7937=0.3968$

$0.4076+0.3968=0.8044$

$\mathrm{Q}_{2}=$

$(0,5) \sum(0.714 * 0.3)(1 * 0.2)(0.5 * 0.15)(1 * 0.2)\left(0.875^{*} 0.15\right)$

$(0,5) \sum(0.2142+0.2+0.075+0.2+$ $0.1312)$

$0,5 * 0.8204=0.4102$

$(0,5)(0.714)^{0.3 *}(1)^{0.2 *}(0.5)^{0.15 *}(1)^{0.2 *}(0.87$ $5)^{0.15}$

$(0,5) \prod(0.9038 * 1 * 0.9012 * 1 * 0.9801)$

$0,5 * 0.7984=0.3992$

$0.4102+0.3992=0.8094$

$Q_{3}$ dsb.... $Q_{10}$

4) Hasil perangkingan dari yang tertinggi hingga yang terendah metode WASPAS 
Tabel 10. Perangkingan WASPAS

\begin{tabular}{|c|c|}
\hline Alternatif & Hasil \\
\hline V8 & 0.9601 \\
\hline V9 & 0.9091 \\
\hline V3 & 0.9008 \\
\hline V10 & 0.8925 \\
\hline V5 & 0.8743 \\
\hline V4 & 0.8735 \\
\hline V7 & 0.8173 \\
\hline V2 & 0.8095 \\
\hline V1 & 0.8044 \\
\hline V6 & 0.7892 \\
\hline
\end{tabular}

3.7 Komparasi Metode WP, SAW, dan WASPAS

Perbandingan metode WP, SAW dan WASPAS dari hasil analisa perhtungan seperti ditampilakan pada tabel berikut :

Tabel 11. Komparasi Metode WP, SAW, WASPAS

\begin{tabular}{|c|c|c|c|}
\hline Rangking & WP & SAW & WASPAS \\
\hline 1 & $\mathrm{~V} 8=0.1118$ & $\mathrm{~V} 8=0.965$ & $\mathrm{~V} 8=0.9601$ \\
\hline 2 & $\mathrm{~V} 9=0.1055$ & $\mathrm{~V} 9=0.914$ & $\mathrm{~V} 9=0.9091$ \\
\hline 3 & $\mathrm{~V} 3=0.1048$ & $\mathrm{~V} 3=0.903$ & $\mathrm{~V} 3=0.9008$ \\
\hline 4 & $\mathrm{~V} 10=0.1039$ & $\mathrm{~V} 10=0.893$ & $\mathrm{~V} 10=0.8925$ \\
\hline 5 & $\mathrm{~V} 5=0.1019$ & $\mathrm{~V} 4=0.885$ & $\mathrm{~V} 5=0.8743$ \\
\hline 6 & $\mathrm{~V} 4=0.1006$ & $\mathrm{~V} 5=0.875$ & $\mathrm{~V} 4=0.8735$ \\
\hline 7 & $\mathrm{~V} 7=0.0942$ & $\mathrm{~V} 7=0.827$ & $\mathrm{~V} 7=0.8173$ \\
\hline 8 & $\mathrm{~V} 2=0.0932$ & $\mathrm{~V} 3=0.820$ & $\mathrm{~V} 2=0.8095$ \\
\hline 9 & $\mathrm{~V} 1=0.0926$ & $\mathrm{~V} 1=0.815$ & $\mathrm{~V} 1=0.8044$ \\
\hline 10 & $\mathrm{~V} 6=0.0909$ & $\mathrm{~V} 6=0.799$ & $\mathrm{~V} 6=0.7892$ \\
\hline
\end{tabular}

\section{Kesimpulan}

Sistem Pendukung Keputusan Penentuan Penerima Beasiswa PMDK dibuat dengan menggunakan analisa perhitungan metode SAW dikarenakan hasil dari analisa perhitungan metode SAW memperoleh nilai preperensi tertinggi dengan nilai Vektor atau V8 $=0.965$ dari metode WP dengan nilai $\mathrm{V} 8=0.1118$ dan metode WASPAS dengan hasil nilai Total kepentingan Alternatif atau Q8 $=0.9601$ yang dapat dilihat pada tabel hasil perangkingan 5.3 diatas. Perolehan hasil analisa yang sama dilakukan oleh peneliti terdahulu [9] yang melakukan perhitungan dengan pengujian data menggunakan metode SAW dan metode WP dengan hasil perangkingan tertinggi diperoleh dari metode SAW dengan nilai 0.79965 dengan metode WP nilai tertinggi 0.18434 . Sementara dari waktu eksekusi metode SAW membutuhkan waktu eksekusi lebih cepat dari pada metode WP dikarenakan metode SAW memiliki proses perhitungan yang lebih sederhana dari pada metode WP seperti penelitian yang dilakukan [10] dengan hasil nilai eksekusi metode metode SAW sebesar 0.4106 detik sedangankan untuk waktu eksekusi metode WP sebesar 0.92 detik.

Metode WASPAS, merupakan gabungan untuk mendapatkan optimalitas berdasarkan kriteria dengan menggunakan metode WSM dan metode WPM. Dari penelitian yang dilakukan oleh [11] telah diamati bahwa metode WSM dan WPM menghasilkan hasil peringkat yang berbeda. Dengan demikian metodologi untuk evalusi akurasi yang berdasarkan pada nilai kriteria awal dikembangkan dengan menerapkan gabungan dari metode WSM dan WPM yaitu metode WASPAS untuk meningkatkan akurasi estimasi yang menerapkan WSM, WPM dan WASPAS untuk evaluasi. Diperkirakan akurasi menerapkan metode WASPAS meningkat hingga 1,3 kali dibandingakan untuk WPM dan hingga 1,6 kali dibandingan WSM. Metode WASPAS diusulkan untuk optimasi tertimbang dengan fungsi agregat yang memungkinkan untuk dijangkau akurasi estimasi tertinggi.

\section{Referensi}

Agus, N. A. F. (2017). Penerapan Metode Weighted Product dan Analitic Hierachy Process Untuk Pemilihan Koperasi Berprestasi. Nur Aini; Fahrul Agus, Volume 9 No.2.

Ali. (n.d.). Kamus Lengkap Bahasa Indonesia Moderen. Pustaka Amani Jakarta.

Mude, M. A. (2016). Perbandingan Metode Saw Dan Topsis Pada Kasus Umkm. Jurnal IImiah ILKOM, 8(2), 76-81.

Aripin, S., Pramadi, A. A., Syahputra, M., \& Silitonga, A. M. (2018). Sistem Pendukung Keputusan Pemilihan Bibit Mangga Terunggul Menerapkan Metode SAW dan WASPAS. Paper presented at the Seminar Nasional Sains dan Teknologi Informasi (SENSASI).

A. S., Rosa dan M.Shalahudin (2018). Rekayasa Perangkat Lunak Terstuktur dan Berorientasi Objek.

Barus, S., V. M. Sitorus, D. Napitupulu, M. Mesran and S. Supiyandi (2018). "Sistem Pendukung Keputusan 
Pengangkatan Guru Tetap

Menerapkan Metode Weight Aggregated Sum Product Assesment (WASPAS)." MEDIA INFORMATIKA BUDIDARMA 2.

Hamberto, A., Katili, P. B., \& Ummi, N. (2013). Pemilihan Supplier Material Berdasarkan Multi Attribute Decision Making (MADM) Menggunakan Metode SAW, WP dan TOPSIS. Hamberto, Arlius, 1(3).

Junaidi, A., \& Visella, F. (2017). Pemilihan Penerima Beasiswa Menggunakan Metode Profile Matching. ParadigmaJurnal Komputer dan Informatika, 19(2), 118-126.

Melia, Y (2016), Multi Attribute Decision Making Using Simple Additive Weighting and

Weighted Product in Inverstment. Internasional Academic Journal Of Business Management 3.
Setyawan, A., Arini, F.Y., \& Akhlis, I. (2017). Comparative Analysis Of Simple Additive Weighting Method and Weighted Product Method to New Employee Recruitment Decision Support System (DSS) at PT. Warta Media Nusantara. Scirntific Journal of Informatics, 4, 40-41.

Targiono, U. L. M. (2017). Sistem Pendukung Keputusan Klasifikasi Keluarga Miskin Menggunakan Metode SAW sebagai Acuan Penerima Bantuan Dana Pemerintah. Uning Lestari; Muhammad Targiono, 8 No 1

Zavadskas, E.K., Turskis, Z., Antucheviciene, J., Zakarevicius, A. (2012), Optimization of Weighted Aggregated Sum Product Assessment. Elektronika ir Elektrotechnika (6), 3-6; 